\title{
A IMANÊNCIA ANALÍTICA
}

\section{JOAO PERCI SCHIAVON}

João Perci Schiavon

Pontifícia Universidade Católica de São Paulo (PUC-SP), Pós-Doutor pelo Programa de Estudos Pós-

Graduados em Psicologia Clínica, São Paulo/SP, Brasil.
RESUMO: Aborda-se a psicanálise, enquanto pensamento prático e clínico, como conquista da imanência. Nesse contexto, a noção de pulsão ganha todo relevo, exigindo, em contrapartida, que sua exploração seja ampliada. Conceito prático, legível como saber em ato, passa a designar um exercício de consistência ética. Uma revisão das versões lacanianas da ética analítica deverá situar devidamente o vetor pulsional. Descrito por elementos da imanência - a força, o vivo e o ativo -, dito vetor constitui o real em psicanálise. A linguagem, nesse campo, se apresenta como uma língua indígena.

Palavras-chave: imanência analítica; saber em ato; ética pulsional; língua indígena.

Abstract: The analytical immanence. Psychoanalysis will be approached, as a practical and clinical thinking, as the conquest of immanence. In this context, the notion of drive gains prominence, demanding in return its development to be magnified. As a practical concept, understood as knowledge in act, the drive designates an exercise of ethical consistency. A review of the lacanian versions of the unconscious ethical status should situate properly the drive vector. Described by elements of immanence - the strength, the "live" and the "active" - such vector is the "real" in psychoanalysis. The language in this field presents the appearance of an indigenous language.

Keywords: analytical immanence; knowledge in act; ethical drive; indigenous language.

DOI - http://dx.doi.org/10.1590/1809-44142018001011 
$\underline{\text { João Perci Schiavon }}$

\section{INTRODUÇÃO}

Compreender o campo analítico como um campo de imanência não constitui novidade, senão pelo uso do termo "imanência", que tem procedência filosófica facilmente identificável. De Spinoza a Deleuze, tratase de algo a ser conquistado. Está lá, por assim dizer, mas precisa ser feito. Não é uma novidade considerar o pensamento analítico como prático e eminentemente clínico. Contudo, deslocá-lo inteiramente para esse campo de imanência parece comportar um rigor necessário, um esforço de precisão a mais, num terreno clínico e conceitual longe de estar esgotado. Tampouco é uma novidade situar o campo analítico numa perspectiva ética. Mas, certamente, damos um passo inédito, ao propor uma nova versão do "estatuto ético do inconsciente".

\section{O QUE SE DIZ DA PULSÃO}

Para descrever adequadamente a "imanência psicanalítica", recorremos à noção de pulsão, que consideramos quase inexplorada, apesar de um consenso silencioso de que a investigação nesse domínio já se esgotou. É fato curioso, senão clínico, que o conceito maior da psicanálise - o mais original, pois toda a metapsicologia se inscreve em seu campo - não comporte mais estranheza, embora esta devesse ser sua característica "constante". Em 1973, em Televisão, Lacan emitia a seguinte observação a propósito da pulsão: “Quem, além de mim, soube arriscar-se a dizer dela o que quer que fosse?" (Lacan, 1973/2003, p. 526). Receamos que a pertinência dessa declaração alcance os dias de hoje.

Considere-se a literatura existente a respeito. Como ela é, conquanto extensa, pouco ousada, repetitiva e, nessa mesma medida, imprecisa, obscura. O que diz, por exemplo, um autor como Luiz Hanns, que se ocupou de explorar todos os sentidos possíveis do termo Trieb em Freud, de modo a esclarecer a "teoria pulsional" e ressaltar sua atualidade no pensamento psicanalítico? Na linha de outros autores, concebe um arco pulsional operando em múltiplos registros:

[...] é das pulsões que se trata em todas as manifestações da vida, seja nos seus aspectos genéricos, seja nas suas formas específicas de manifestação: como força da mãe natureza, como instinto biológico, como estímulo nervoso na fisiologia, como imagem do desejo nas alucinações do bebê, ou como pensamento. (HANNS, 1999, p. 161)

A consideração isolada de qualquer uma dessas manifestações "transforma a teoria pulsional em algo de outra ordem, (...) numa teoria dos impulsos, dos afetos e das imagens, ou em uma teoria da linguagem, ou em uma teoria organicista, ou em uma teoria biológica ou ainda em uma teoria metafísica" (HANNS, 1999).

Todos esses campos ativados, na origem e em última instância, pelo móvel pulsional, expressam, evidentemente, uma realidade complexa e objetiva. Mas a escuta freudiana se demora na apreensão de todos esses aspectos da experiência humana? É preciso, antes de tudo, alcançar o ponto de vista pulsional e sua incidência clínica. Ao dizer que qualquer redução dessa complexidade de expressões e definições do arco pulsional resultaria em uma teoria limitada e tendenciosa (biológica, linguística ou metafísica), Luiz Hanns não parece ainda levar em conta a pulsão a partir dela própria - que é o ponto de vista psicanalítico por excelência. Aquele autor, no entanto, observa que

[...] na escuta analítica não se trata de operar com uma outra lógica que a do consciente, a saber, a do inconsciente, mas com uma somatória de lógicas, ou melhor, com a simultaneidade de leis de regulação pulsional, bem como com determinações mútuas entre instâncias diversas. É claro que o foco central da escuta se dá sobre o inconsciente dinâmico; contudo, este também contém materiais já elaborados em linguagem e em parte ordenados conforme as leis do pensamento consciente. (HANNS, 1999, p. 155)

De fato, a escuta do inconsciente envolve a atenção aos processos oriundos de outras instâncias. Essa inclusão, porém, não esclarece a natureza da escuta e a direção da análise. Perde-se de vista a determinação pulsional segundo a qual se ordenam todos os processos, mesmo que eles se ordenem ao avesso e de maneira 
confusa, intrincada, com sentido inverso, ou rasurado quanto às procedências. Simplicidade da análise, destinada a restaurar uma ordem. Na medida em que subordina a si as demais lógicas e os demais saberes, é de fato a lógica do inconsciente ou, para sermos precisos, o saber pulsional quem preside o processo analítico e decide sua direção. Mas onde aporta Luiz Hanns ao pensar a pulsão "na clínica de Freud"? Embora circunscreva sua pesquisa à obra freudiana, dirá ao final o que prevalece no entendimento analítico até os dias de hoje:

A tarefa analítica também pode ser entendida como tornar o Es acessível (pelo desrecalcamento) à influência (não ao domínio) do ego (o qual opera com Vorstellungen) e obter a Bändigung e Berwältigun, isto é, a regulação dos fluxos pulsionais de acordo com os princípios do ego, visando ressignificar as pulsões para tornálas ichgerecht (egossintônicas, de acordo com o ego, harmônicas com o ego). (HANNS, 1999, p. 186)

Trata-se de administrar, regular e harmonizar os fluxos pulsionais conforme os interesses ou os princípios de certa subjetividade.

Há toda uma vertente do pensamento psicanalítico na qual a pulsão é tratada como constructo teórico, como ficção, ou seja, concebida somente sob seu aspecto representacional. Freud teria dado ocasião a essa interpretação do conceito: “A teoria das pulsões é, por assim dizer, nossa mitologia”. Para Garcia-Roza, por exemplo, a pulsão se destina a uma descrição do real que o produz como "ficção autenticamente científica" (GARCIA-ROZA, 1996, p. 115). Esse autor sustenta que a pulsão "nunca se dá por si mesma (nem a nível consciente e nem a nível inconsciente), ela só é conhecida pelos seus representantes: a ideia (Vorstellung) e o afeto (Affekt). Além do mais, ela é meio física e meio psíquica. Daí seu caráter mitológico" (idem). Não se pensa, assim, o seu exercício - a pulsão como práxis e como clínica.

De modo mais radical, Fabio Herrmann destitui o interesse clínico da noção: "As teorias diversas que compõem a metapsicologia freudiana, como o nome o diz, formam uma espécie de metafísica da psique e possuem, como tal, valor operacional interpretante; valor, porém, que só é vigente nos campos teóricos" (HERRMANN, 2004, p. 85). Reduzida ao horizonte metafísico da teoria e desconhecida sua enorme plasticidade, a noção de pulsão, que devia ser o alfa e o ômega da clínica, perde sua força e se torna clinicamente inútil.

Em Lições sobre os sete conceitos cruciais da psicanálise, de Juan David Nasio, já não figura o conceito de pulsão, um dos quatro fundamentais para Lacan, e tão somente o de sublimação (que aparece ao lado dos conceitos de castração, de foraclusão, de narcisismo, de falo, de supereu e de identificação). De fato, podemos assimilar a noção de pulsão à de sublimação, diretamente, sem desvio. Aliás, é o que fazemos, mas não por um privilégio conceitual da segunda sobre a primeira. Na verdade, é a pulsão que estabelece os termos originários da sublime-ação. A plasticidade da pulsão, destacada por Nasio, define um aspecto importante da sublimação, mas não esclarece sua determinação primeira: em que consiste seu exercício? A que ela responde? Além disso, esse autor conjuga de modo inextricável sublimação, narcisismo e ideal de eu (NASIO, 1989), sendo que estes últimos não somente são conceitos alheios ao de pulsão, remetendo a instâncias psíquicas que resistem ao processo pulsional, como compreendem, por isso mesmo, uma reação à análise. Dão assim testemunho inequívoco de uma direção não pulsional. Por que embaralhar o que Freud distinguira com suficiente precisão? A sublimação é um processo distinto da formação de ideal e, por ser da ordem da pulsão, avessa ao narcisismo (Freud, 1915/2010).

Para alguns autores, a pulsão é essencialmente de morte, seguindo nisto - de perto ou à distância - a Lacan, que a qualificou de parcial e, por excelência, de morte (LACAN, 1966/1989). Não é a nossa posição, porém não desconhecemos que essa definição foi necessária em determinado estágio do pensamento psicanalítico. Ao longo da especulação analítica, a morte se deslocou. Da morte como finalidade, em uma primeira leitura de Freud (Além do princípio do prazer), à morte como processo, tal como será tratada por diversos autores, é todo um entendimento acerca da pulsão que se altera e se aprofunda, sem que se possa 
$\underline{\text { João Perci Schiavon }}$

dizer que essa alteração não estivesse virtualmente presente em Freud. No desenvolvimento da cultura, é a ação da pulsão de morte, segundo Garcia-Roza, que garante a eternização do desejo, caracterizado pela diferença, ao contrário da ação da pulsão de vida, que investe na homogeneização do humano e na formação de unidades indivisíveis. A pulsão de vida contribuiria assim para a morte do desejo (GARCIA-ROZA, 1990). Jô Gondar, fazendo coincidir tempo e pulsão, soube exprimir concisamente essa corrente de pensamento analítico. Observa que a pulsão de morte introduz uma não-ligação, um vazio de sentido que o psiquismo, desenvolvendo suas estratégias, busca capturar, dominar. "Podemos considerar a pulsão como determinante da temporalização humana: é o seu tempo selvagem e não-ligado que o psiquismo tentará dominar, produzindo modos de encadear lógica ou cronologicamente o antes e o depois, transformando o tempo puro em ordenações temporais" (GONDAR, 1995, p. 123). Ou ainda: "Não poderíamos pensar o tempo da pulsão de morte sem enfatizar o seu aspecto demoníaco, que faz advir a dispersão e o excesso a uma superfície precariamente equilibrada, ameaçando-a constantemente de dissolução" (ibidem, p. 104). Mas se - como tem demonstrado nossa investigação - a pulsão mobiliza o psiquismo por contrariedade, se impõe um limite e uma indeterminação frente ao que estava determinado, concluído e deveria durar, não o faz por ser, de seu ponto de vista - porque ela é um ponto de vista -, ausência de ordem, dispersão e caos, e, sim, por insinuar, incessantemente, uma ordenação superior nos chamados processos humanos, relativa a outra altura do tempo. Daí advém o conflito, o embate, que envolve as modalidades de visão das instâncias que se enfrentam, dentre elas uma visão psíquica, imaginária e narcísica, porém não menos simbólica, cultural e metafísica, de que a pulsão é dispersão e caos. Aquela ordenação superior se definirá, todavia, segundo seus próprios critérios, analiticamente discerníveis nas formações do inconsciente.

Revimos brevemente certas linhas de pensamento psicanalítico sem pretender que alguma delas seja exemplar. Outras poderiam ser evocadas, mas fugiria dos objetivos deste artigo. As que destacamos sugerem que a pesquisa no campo da pulsão encontra-se estacionada. Essa suspensão se deve à inoperância do conceito frente ao avanço do pensamento e da clínica, ou à dificuldade de acesso ao campo pulsional, depois de dados os primeiros passos?

\section{QUATRO VERSÕES DO ESTATUTO ÉTICO DO INCONSCIENTE}

O que faltou dizer acerca da pulsão? É um vasto continente, para fazer aqui alusão a uma prospecção de Freud. Mas uma asserção a respeito pode ser adiantada, com a possibilidade de deslocar - se bem fundada boa parte do pensamento psicanalítico. A pulsão não constitui apenas um problema de natureza ética, exigindo estratégias psíquicas e culturais à altura de seus desafios. Ela mesma é de consistência ética. A nova exploração do campo pulsional que essa asserção mobiliza, exige, como um correlato necessário, que o estatuto ético do inconsciente, tal como foi enunciado por Lacan (LACAN, 1998), seja revisto, redimensionado. Isso porque se deve a esse autor, em especial, que a análise fosse situada eticamente em sua função, a partir, inclusive, do desejo do analista, desde então vinculado à direção do tratamento de modo irrevogável. Sua obra apresenta pelo menos três versões da ética analítica que não se excluem. Numa primeira, a ética consistiria em não se abrir mão do desejo; numa versão seguinte se formularia como ética do bem dizer e, finalmente, na chamada segunda clínica de Lacan, caberia ao sujeito se responsabilizar pelas formações do inconsciente, ao contrário de ser abonado por ele. Propomos uma quarta versão, que não revoga as anteriores, mas ordena-as segundo uma direção até hoje apenas pressentida. Ela nos serve de fio condutor no tratamento das outras três, de modo que, aos poucos, estará sendo igualmente formulada.

Seja a primeira versão da ética analítica, em que se trata de não abrir mão do desejo. Por que nos parece aceitável uma proposição ética dessa natureza, se envolve uma dimensão de escolha que deveria ser, a princípio, inconsciente, uma vez que, como é de supor, não se está considerando um desejo consciente ou pré-consciente? A questão ética só pode se referir a um desejo distinto de qualquer propósito ou projeto, um desejo, portanto, à altura do inconsciente. 
Se pensarmos em Antígona, de Sófocles, podemos extrair algo que esclareça a natureza desse desejo, até porque é no seminário em que Lacan retoma essa tragédia, fazendo de sua protagonista a heroína do desejo, que ele enuncia o que chamamos de primeira versão ética da análise (LACAN, 1960/1987).

No texto de Sófocles, Antígona é considerada inflexível como o pai. Ora, é de firmeza que se trata. Não importa o que esteja em jogo, a condição de desejo, tornada absoluta, decide pelas demais condições de existência, sejam elas biológicas, culturais ou afetivas - as diversas faces, dir-se-ia, de uma sujeição ao Outro (LACAN, 1960/1998, p. 828). Antígona só reconhece as leis do céu, e, nesse embate extremo, envolvendo a vida e a morte, sua atitude é de inteiro desprendimento. Este qualifica o desejo, sua feição superior, extra pessoal. Que o desejo seja autônomo em relação à lei, posto que ela deriva dele (LACAN, 1960/1998), significa que não está sujeito (ou assujeitado) a quaisquer condições de existência que vigorem no mundo humano. É o desterritorializado. Existe algo de extra-terrestre no desejo, e Antígona poderia dizer com o Cristo: eu venci o mundo.

As formações do inconsciente anunciam um novo nascimento, assim como descrevem inumeráveis abortos. Todavia, o novo começo não elimina, não importa em que sentido, a importância dos fatores biológicos e culturais. Não se trata de um além-túmulo "espiritual”. Não é um problema de eliminação ou de exclusão daqueles fatores, mas de subordinação. Na composição e recomposição das forças, reside o caráter ético do novo começo que, em contrapartida, deve ser constante. "Eu reconstruirei o homem que sou", dizia Artaud, concebendo um corpo que não pudesse mais ser ferido. Esse corpo é indissociável de um novo dizer. É o corpo da sublime-ação.

Eis, portanto, a segunda versão do estatuto ético do inconsciente: a ética da análise é a do bem dizer, que se deve igualmente a Lacan, isto é, à necessidade ética e à precisão clínica com que destacou o real da linguagem - em nossos termos, a língua indígena. É um aperfeiçoamento da fórmula anterior, que prescrevia não ceder do desejo. Não se efetua o bem dizer ou o dizer como tal sem que uma subjetividade opere na altura do inconsciente. O bem dizer e a conquista do inconsciente são assim convergentes. Conforme sugerimos acima, as formações do inconsciente são ensaios mais ou menos bem sucedidos de sublimação, de tal modo que esta se esclarece, no plano das forças, como um domínio, inclusive porque, com igual propriedade, poderíamos dizer que aquelas formações são de poder.

Talvez seja mesmo a atividade poética o que melhor ilumina o exercício da pulsão. Daí transitarmos da pulsão ao dizer sem qualquer mediação, deslocamento ou desvio. Felix Guattari adota claramente essa transição direta quando propõe uma ampliação da abordagem dos modos de subjetivação parcial (e, portanto, pulsional), a partir de análises como as de Bakhtine sobre a poesia:

[...] a subjetividade criadora, para se destacar, se autonomizar, se finalizar, apossar-se-á, de preferência: 1) do lado sonoro da palavra, de seu aspecto musical; 2) de suas significações materiais com suas nuanças e variantes; 3 ) de seus aspectos de ligação verbal; 4) de seus aspectos entonativos emocionais e volitivos; 5) do sentimento da atividade verbal do engendramento ativo de um som significante que comporta elementos motores de articulação, de gesto, de mímica, sentimento de um movimento no qual são arrastados o organismo inteiro, a atividade e a alma da palavra em sua unidade concreta. E, evidentemente [...], é esse último aspecto que engloba os outros. (GUATTARI, 1998, p. 26)

Esse último aspecto é o que, de nossa parte, chamamos de dizer, ou seja, a atividade apropriativa por excelência, a integridade que ela transmite a todos os elementos implicados (conforme o caráter ao mesmo tempo simples e refinado da pulsão) e sua soberania sobre os demais fatos da existência. Atividade, integração, soberania.

Deixe seu sentido do ritmo se insinuar, circular por entre os homens e as mulheres, os veículos, os pardais, tudo o que acontece na rua - até que tudo esteja ligado a um todo harmonioso. Talvez seja essa sua tarefa: encontrar a relação entre coisas que parecem incompatíveis e que, no entanto, têm uma afinidade misteriosa, 
absorver toda a experiência que se oferece a você, sem temor e na sua plenitude, de tal modo que o seu poema seja um todo, e não um fragmento. (LAPOUJADE, 2013, p. 41)

$\mathrm{O}$ "todo" de que fala Virginia Woolf em $A$ arte do romance, considerado em sua integridade mais que em sua completude - não se distinguindo, por isso, de um devir ("Deixe seu sentido do ritmo se insinuar, encontre a relação entre as coisas, absorva toda a experiência, sem temor...") -, remete a um dizer igualmente íntegro, indissociável de uma apropriação, de uma conquista.

Algo desse domínio comparece na mais cotidiana formação do inconsciente. Mas tal formação não é o que escapa ao meu domínio? Sim, sob o aspecto de uma dominância, de uma força superior. É a isso que devo prestar atenção: força superior e, a crer na metapsicologia freudiana, força constante. É o que me dá o fio condutor da análise, me permitindo concluir que uma vida - em seu alto tempo - não se distingue de um dizer.

O que reúne os aspectos relevantes, afetivos - da palavra e da fala - é sua duração, a imponderável duração, pela qual o dizer se esclarece feito uma essência, um extrato de certa altura do tempo, sub speciae aeternitatis. Lacan possivelmente se reporta a tal essência singular, algo spinozista, ao conferir a Joyce a decisão de chegar "ao ponto extremo de encarnar nele o sintoma, através do qual ele escapa a toda morte possível (...)" (LACAN, 2007, p. 163). A despeito do próprio Lacan, que ironiza a tendência de Joyce a se ver como redentor, o artista - ao menos quanto a si - acerta o alvo.

O tema do bem dizer anima internamente as duas outras versões da ética analítica. Para introduzi-las, citamos mais uma vez Lacan, referindo-se à palavra freudiana: "Freud oferece o testemunho em si mesmo deste lugar indivisível do que diz, construindo o responsável herético de sua palavra" (LACAN, 1976-1977). Registramos na frase a equivalência, como estivemos repisando, de uma vida e um dizer, não sem ressaltar a integridade de uma e de outro, não sem enfatizar que se trata de uma e mesma coisa. É o que está pressuposto nessa menção a um lugar indivisível, contrariando a famigerada divisão do sujeito que os analistas não cessaram de insinuar no cadinho teórico e clínico. É que esse lugar indivisível, do qual Freud daria testemunho, é imediatamente singular e extra-pessoal, e daí advém sua condição de escolha - em grego, haeresis. As consequências dessa posição, como se sabe, vão muito além de interesses pessoais, narcísicos, de uma classe ou uma cultura. Seu parentesco com a peste foi assinalado pelo próprio Freud.

A terceira versão da ética analítica aproxima inconsciente e responsabilidade, título, aliás, de um livro de Jorge Forbes, espécie de derivação de algumas teses de Jacques Alain Miller, e que servirá de referência na formulação dessa versão, de maneira a estimarmos suas consequências teóricas e clínicas. Diferentemente das outras duas versões, esta parece - embora oportuna a princípio - mais imprecisa e sujeita a reordenações, a ajustes, quando não a severas críticas.

A noção de responsabilidade no domínio analítico ganhou nova relevância com o seminário $O$ sinthoma, onde aparece em diferentes articulações, sempre reportáveis, pelo que tudo indica, ao que Lacan chamou de "desabonamento do inconsciente". A novidade clínica que a expressão inédita ("desabonado do inconsciente") indicaria não é assim tão nova. A chamada "retificação das relações do sujeito com o real" (LACAN, 1958/1998, p. 604) já continha, nela mesma, o desabonamento do inconsciente. Seja como for, tornou-se corrente pensar, no âmbito da escola lacaniana, que o final da análise consiste na identificação ao sinthoma, entendendo-se que este seja o reduto da singularidade, o lugar de não-senso, o osso que restou da operação analítica, o não analisável. Quê fazer, senão responsabilizar-se por esse osso, esse núcleo de nãosenso e, a partir daí, "inventar uma forma de articular-se no mundo" (FORBES, 2012, p. 167)? Dizer que Joyce é um desabonado do inconsciente serve para descrever, em nova versão, a condição de um final de análise: $o$ inconsciente não abona mais nada. Não posso recorrer a ele como medida de minha ignorância, como a um saber que me desresponsabiliza dos atos, dos acasos e acidentes.

Mas alguma vez me desresponsabilizou? Que noção clínica vigorava anteriormente? Seja o paciente hipocondríaco cujo sintoma remanescente, uma tontura, era, na verdade, tontice. O medo de sofrer uma 
tontura avassaladora, que o prostrasse em público a qualquer momento, foi se demonstrando, aos poucos, um pensamento tonto (a tontura nunca ocorreu de fato), e finalmente uma tontice. Certo dia, em análise, informa que irá consultar uma psiquiatra homeopata que dispõe do medicamento indicado para curá-lo da tontura. Que não volte à análise, responde-lhe o analista, enquanto estiver tratando dessa tontura. Ele oscila entre perplexo e indignado com a resposta, mas se ausenta para o tratamento. Retorna após um tempo, reconhecendo que não podia esperar do analista uma tontice tal que levasse a sério a tontura já analisada e a intenção de tratá-la com medicamento.

A segunda clínica, com a qual se empresta consequência, de acordo com Forbes, distingue-se da primeira, na qual se busca o sentido. Mas que o sentido da tontura seja a tontice tem consequência imediata nos atos. A tontura, na verdade tontice, é um ato de pensamento que será sustentado ou não, embora constitua, curiosamente, um saber - saber do ato ou em ato. É preciso conceber o sentido não mais sob a égide da representação, nem da fantasia, mas pragmaticamente, e ainda segundo o pragmatismo pulsional que, como pensamos, não se distingue do saber (prático) da pulsão. Ora, esse saber é eminentemente clínico.

Uma das teses de Miller procura afastar a ideia de cura da práxis analítica, atitude que se tornou lugar comum no meio psicanalítico e mesmo, malgrado sua crítica, no meio psicoterápico em geral. "[...] O que diz essa nova ou segunda clínica? Bem mais do que a primeira, ela invalida, ridiculariza a ideia de cura, relativiza o efeito terapêutico" (MILLER, 2008, p. 4). Argumenta que o mundo social espera precisamente esse efeito da psicanálise. O sinthoma, enquanto alvo da análise e núcleo incurável, indica a dissonância real dessa prática em relação às expectativas da cultura. A tese de que "todo mundo é louco, isto é, delirante" (ibidem, p. 4), aposta nessa incurabilidade radical que resiste a qualquer ideal social de saúde, felicidade, bem-estar, normalidade etc. Essa aposta afirma a "inadequação do real e do mental, e que do real só se pode dizer (o) falso, só se pode mentir" (idem). Por mais que uma posição analítica, de cunho estratégico, se esquive assim das pressões do mundo, perde de vista, nessa altura do argumento - e por um equívoco ético -, que o real é da ordem da força, do exercício, da prática. O acesso a essa prática não coincide, obviamente, com nenhum ideal social. Muito pelo contrário. Raro, difícil, porém não impossível, o acesso ao real não é outra coisa que a conquista da imanência.

Mas estamos diante de malversações do pensamento psicanalítico, nomeadas de "finezas". O saber e sua capitulação frente ao não-saber, e o inconsciente, por consequência, como o lugar do abono e do que não serve para muita coisa, ou melhor, como o que nos desvia, finalmente, do alvo analítico (o "não saber"). As duas malversações aparecem articuladas às noções de singularidade e de sinthoma:

[...] desabonado do inconsciente quer dizer simplesmente [...] que aquilo (Finnegans's Wake) [...] não nos toca, não mexe com nosso objeto $a$. Lacan afirma: isso não tem a ver com equívoco algum que possa emocionar o inconsciente de quem quer que seja. Não é simplesmente a crítica de um leitor, é aquilo que o conduz a dizer: aqui não há inconsciente. É, portanto, a obra de alguém separado, obra de um exilado, [...] algo absolutamente singular. Vejam o que esse termo, singular, traz consigo: a distância de qualquer comunidade. Nada de comum. É fechado sobre si mesmo. (MILLER, 2008, p. 59).

Perde-se assim de vista que o singular, quando referido à pulsão, seu esteio legítimo, é igualmente extrapessoal ou impessoal. Logo, não é fechado em si mesmo, sua abertura não sendo senão a do inconsciente. Este designa um processo extra-pessoal de singularização. Não são justamente os fenômenos analíticos singulares que nos dão acesso privilegiado a ele? A condição de desabonado do inconsciente não autoriza a pensar que não há mais inconsciente, pois o inconsciente nunca abonou coisa alguma. Sua razão de ser nunca foi esta, e, sim, o deslocamento ético e clínico do pensamento, pela exploração minuciosa - a análise - da força pulsional. Ainda que Miller procure distinguir o singular do particular, a imprecisão domina. "Procuro o bom uso do sinthoma na prática da psicanálise porque ele designa [...] o que há de singular em cada indivíduo. [...] Procuro porque ainda não encontrei como formulá-lo, como bem dizê-lo" (MILLER, 2008, p. 63). Daí ser quase natural o deslize para uma dimensão particular e pessoal. 
$\underline{\text { João Perci Schiavon }}$

Finalmente [...] reaparece o sintoma particular, não decifrável, intratável. É um aspecto da pessoa e do qual ela não consegue se desvencilhar, nem pela compreensão de seu sentido, nem pela tentativa da igualdade ou equivalência aos outros. É um sintoma que identifica alguém pelo fato de não poder deixar de ser. (FORBES, 2013, p. 165)

Embora pareça haver uma evolução na "segunda clínica", uma mudança de perspectiva, um remanejamento do dispositivo analítico e de seu alvo, o deslocamento do que seria a primeira para a segunda apenas denuncia a ignorância, em sentido analítico, do que se encontra em jogo desde o início da psicanálise, a saber, um processo ético de dimensões ainda pouco conhecidas.

Antes, diz ainda Forbes, era o saber do sintoma, o gozo desse saber; agora, com Lacan e Joyce, é o gozo de um não saber (FORBES, 2013). Será mesmo isso que se deve entender por um saber de "não senso", associado ao bem dizer - que é antes um não saber?

É a tergiversação em torno do "saber de não senso", não compreendido como saber, o que significa não atingido. É preciso enfatizar que é um saber em ato? A propósito, o que faria Lacan evocar, em sua língua indígena, o gay sçavoir (LACAN, 1973, 2003, p. 525)?

A responsabilidade convocada pela análise existe na medida do saber inconsciente. Tal medida requer, portanto, o discernimento de que o saber em questão, de valor pragmático-pulsional, aspira à sua prática constante. Desse ponto de vista, o saber e a responsabilidade são uma e mesma coisa. Longe de ser eludida pelo recurso ao inconsciente, má-fé já denunciada por Sartre, a responsabilidade é afirmada em uma subjetivação pulsional, extra-pessoal. Aqui, ademais, se deixa apreender o que chamamos de ética da pulsão e o que pensamos acerca do real em psicanálise.

Porque o inconsciente é uma prática e, como tal, uma ética - ao contrário, agora, do que pensava Sartre - da qual, justamente, temos pouco conhecimento, isto é, pouca prática, ao menos no grau de lucidez e de ousadia que ela requer. $\mathrm{O}$ argumento milleriano se funda, contudo, na noção de gozo:

A orientação para o singular não quer dizer não decifrarmos o inconsciente. Ela quer dizer [...] que essa decifração se interrompe no fora de sentido do gozo e que, ao lado do inconsciente, onde isso fala, [...] há o singular do sinthoma, onde isso não fala a ninguém. [...] Aqui, estamos num nível que difere do inconsciente, uma vez que a descoberta freudiana, tal como formulada por Lacan, propõe o inconsciente como redutível por completo a um saber. A redução do inconsciente a um saber, ou seja, a uma articulação de significantes [...] é exclusiva do inconsciente. [...] O objeto $a$ era sempre um elemento de gozo pensado a partir do inconsciente, a partir do saber, ao passo que o ponto de vista do sinthoma consiste em pensar o inconsciente a partir do gozo. (MILLER, 2008, p. 70)

Ao lado do inconsciente, diz Miller, há o singular do sinthoma. Dizer que "no fora do sentido do gozo [...] estamos num nível que difere do inconsciente", pois o inconsciente é "redutível por completo a um saber", e que este se resolve numa "articulação de significantes", é desconhecer que em Freud, ao menos, esse saber está longe de se reduzir a tal articulação; ou seja, que ele envolve o que dizemos - a força, como um poder de avaliação, e o afeto, como avaliação do que é decisivo ou mais importante na disposição das forças. A proposição, que está na origem daquela concepção de inconsciente, de que somente os significantes são recalcados, não só não é freudiana como exige uma profunda revisão. No texto $A$ negativa, por exemplo, Freud observa que a liberação da ideia pelo procedimento denegatório não suspende o essencial do recalque. Este visa, sobretudo, o afeto e seu desenvolvimento, isto é, sua expressão em atos. Não é preciso dizer mais. Pensar o saber como mera articulação significante é limitá-lo à sua expressão mais rarefeita, é perder de vista todo o pragmatismo pulsional. Neste, o gozo aparece como saber conquistável. Pensar o inconsciente a partir do gozo significa pensá-lo a partir de um saber de não-senso, pulsional.

Uma palavra ainda sobre a dimensão singular do gozo. Ela se propõe em diferentes alturas, repercutindo, todo o tempo, o grau de exercício ético de que se é capaz. Logo, é muito vago, tímido e finalmente obscuro falar apenas em gozo, em fora do sentido e em não-saber, asseverando que essa é a perspectiva singular do 
sinthoma e o alvo da análise. Mas compreende-se, uma vez que a ordem de saber em que se inscreve o sinthoma não alcança seu fora senão negativamente.

\section{UMA ÉTICA, UMA CLÍNICA E UMA POLÍTICA}

O que nos leva, então, a rever a noção de pulsão, para além de tudo o que se disse em termos conceituais?

Primeiro, pensamos que não se deva abandonar a ideia de força; esse conceito vitorioso, segundo Nietzsche, e que desapareceu no lacanismo. Seria preciso, no entanto, verificar a natureza da força que interessa à psicanálise, como concebê-la de maneira a não recair na opacidade de um conceito já denunciada por Lacan. Duas ideias são decisivas, a nosso ver, para o pensamento analítico no concernente à força: a de constância (konstant Kraft) e a de comando e subordinação. No primeiro caso, trata-se de elevar até a firmeza ética a força constante (uma das suas fórmulas é a de não abrir mão do desejo); no segundo, de sustentar a determinação ética do pensamento através da qual se ordenam os processos subjetivos. As formações do inconsciente dão testemunhos inequívocos da conjugação desses dois fatores: a constância de uma questão inconsciente e o modo como ela comanda o devir psíquico, por mais que o faça obscuramente. Ora, é a luminosa concepção de combate em Freud, acrescida de uma inspiração nietzschiana, colocando em jogo forças ativas e reativas, que deveria ser mantida e depurada. É pela noção de força que a metapsicologia se revelará, finalmente, uma ética e uma política. As forças são indicadores imediatos do afeto e de sua ciência avaliadora, todavia ignorada como ciência, a despeito da renovação que a psicanálise operou na ordem do saber. Sobre o que esse gênero de avaliação decide? Sobre o que é o mais importante do ponto de vista das forças. E o que é o mais importante desse ponto de vista? A continuidade, quando não o aumento gradual, daquele poder de avaliação e, por extensão, de sua ciência prática.

Segundo, pensamos que o real, além de designar a força, designa igualmente o vivo, tal como se apresenta (e não como se representa) na altura da experiência humana, inclusive ali onde essa experiência encontra seus limites, tanto acima como abaixo, mas também em sua tendência (Trieb) a avançar além de si mesma. Vale pensar que, quanto mais o vivo "se esclarece", quanto mais luz (ou lucidez) adquire na escalada de seus graus, mais vida ou vitalidade descobre em si, conhecendo gradualmente o que pode. Pulsão, tal é o nome encontrado pelo pensamento psicanalítico para designar a equação do vivo, da lucidez e dos seus graus ainda não exercidos.

Consideramos, portanto, dois aspectos do vivo na altura do humano (ou do dizer): sua graduação e sua linguagem. Através desta, com maior ou menor clareza, convoca e reúne as forças disponíveis, incluindo as que se encontram em seu entorno ("deixe seu sentido do ritmo se insinuar..."). Em casos de singularização avançada, vê-se germinar e crescer "uma língua estrangeira dentro da própria língua". Mas tal manifestação, com seu teor de estranheza e singularidade, difunde-se secretamente por toda a experiência humana, se tivermos em conta as formações do inconsciente. Por isso, Lacan demarcou a letra, exprimindo essa fronteira onde vida e linguagem se tornam indiscerníveis. A língua "é viva porque a criamos a cada instante" (LACAN, 2007, p. 129). Mas a vida da linguagem é apenas uma aproximação do que realmente interessa do ponto de vista analítico, a saber, a linguagem do vivo. Este permaneceria vago, demasiado genérico, se não o esclarecêssemos pela noção de pulsão, cuja exploração, conforme observamos no início deste artigo, apenas começou.

Terceiro, que a pulsão seja essencialmente atividade, como pensava Lacan, é da maior importância conceitual e clínica. A atividade, também ela, deve ser elevada à decisão ética. De tal modo que a "retificação com o real" já mencionada não é somente o primeiro passo da análise, mas seu passo constante. Essa terceira razão para conservarmos a noção de pulsão e esmiuçá-la em suas possibilidades nos permite falar em força ativa - vis activa -, entendendo que a expressão designa uma potência ética em exercício. 
A força (ou a potência), o vivo (ou o afeto) e o ativo (ou a condição de escolha), tais são os elementos da imanência, instauradores do campo analítico - o real da psicanálise. Cada um desses termos, esclarecendo-se pelos demais, nos remete à pulsão.

Só a imanência é clínica, se pensarmos analiticamente. O ponto de vista da imanência é o da pulsão mesma. Ela não é dada, é construída, colocando em primeiro plano a dimensão prática e ética do pensamento.

Assim, além de ser parcial e de morte (embora estas ainda sejam imagens da pulsão, distintas de uma visão pulsional), além de ser uma força constante, de ser essencialmente atividade, de ser sexual e de vida, a pulsão é um exercício, uma medida, um critério e uma perspectiva.

Exercício em graus diferentes de obscuridade e de clareza, e cuja direção é dada pelo real, ou seja, pela pulsão mesma. Enquanto força constante, ela aspira a uma prática igualmente constante. É o que chamamos de dobra pulsional. Talvez valha reforçar que a constância diz respeito à irrevogabilidade da questão ética. Desse modo, aquele exercício se gradua desde as formações do inconsciente até a sublimação originária.

Medida, porque mensura, a cada vez, suas condições de exercício - pelo que é um poder de avaliação de seus diferentes graus de vitalidade, de potência e lucidez. Chamamos de afeto a esse gênero de avaliação, e recorremos à noção de afeto originário para designar o regime extra-pessoal do afeto. Aí reside o saber pulsional, saber das próprias condições de exercício. Esse saber é, por assim dizer, a medida analítica, o mais singular dos metros. É saber de não-senso porque não recebe luz de nenhum outro. De uma perspectiva pulsional, é o único que faz sentido (ou seja, todos os outros se ordenam em vista deste).

Critério - de que natureza? Ético e imediatamente clínico. É que não há diferença entre o critério ético e o clínico. E isso deveria orientar nossa concepção de cura, ao invés de abdicarmos de qualquer cura em nome de um cinismo esclarecido. A consistência ética da pulsão situa a clínica no real, afastando-a, portanto, dos ideais de eu e aproximando-a do coração de nosso ser (Kern unseres Wesen) - que, diga-se de passagem, não é necessariamente o ser, mas, antes, a atividade em que ele consiste. Isso apenas reassevera a retidão pulsional. Sim, existe uma direção da análise, e é mesmo o analista quem a dirige, na medida em que ouve a pulsão.

É uma perspectiva no tempo, um ponto de vista a certa altura do tempo. O intempestivo nietzschiano se aplica perfeitamente à pulsão, pois ela é o processo pelo qual o mais estranho dos tempos se insinua nas condições atuais de vida. Sendo o alto tempo de uma vida, escorre aqui e ali, em gotas, quase inadvertido. A concepção de um tempo próprio à pulsão de morte mencionada incialmente - tempo não reconciliado, selvagem ou demoníaco - deve ser revista. É ainda uma imagem da pulsão e seu tempo, cuja ordenação superior, de modo geral desconhecida, se torna sensível, audível, na decifração pragmática do inconsciente.

Recebido em: 14 de junho de 2015. Aprovado em: 3 de novembro de 2015.

\section{REFERÊNCIAS}

DELEUZE, G.; GUATTARI, F. Mil platôs. São Paulo, Editora 34, 1997.

FORBES, J. Inconsciente e responsabilidade: psicanálise do século XXI. São Paulo: Manole, 2012.

FREUD, S. Obras completas. V. 12, São Paulo: Companhia das Letras, 2010.

GARCIA-ROZA, L. A. Introdução à metapsicologia freudiana. Rio de Janeiro: Zahar, 1991.

. Freud e o inconsciente. Rio de Janeiro: Zahar, 1996.

GONDAR, J. Os tempos de Freud. Rio de Janeiro: Revinter, 1995.

GUATTARI, F. Caosmose: um novo paradigma estético. Rio de Janeiro: Editora 34, 1998.

HANNS, L. A teoria pulsional na clínica de Freud. Rio de Janeiro: Imago, 1999.

HERRMANN, F. Introdução à teoria dos campos. São Paulo: Casa do Psicólogo, 2004.

LACAN, J. A ética da psicanálise. Rio de Janeiro: Zahar, 1987. (O seminário, 7).

. Escritos (1966). Rio de Janeiro: Zahar, 1966. 


\section{A imanência analítica}

seminário, 24).

L'insu que sait de l'une-bévue s'aile a mourre (1976-1977). Rio de Janeiro: Zahar, inédito. (O . O sinthoma. Rio de Janeiro: Zahar, 2007. (O seminário, 23).

11).

Os quatro conceitos fundamentais da psicanálise. Rio de Janeiro: Zahar, 1998. (O seminário, Outros escritos. Rio de Janeiro: Zahar, 2003.

LAPOUJADE, D. Potências do tempo. São Paulo: N-1 Edições, 2013.

MILLER, J. A. Coisas de fineza em psicanálise. Documento de trabalho para os seminários de leitura da Escola Brasileira de Psicanálise, lições de I a IV. 2008. Disponível em: <http://institutopsicanalisemg.com.br/horizontes/textos/licoes.pdf>. Acesso em: 05 abr. 2015.

NASIO, J-D. Lições sobre os sete conceitos cruciais da psicanálise. Rio de Janeiro: Zahar, 1989.

\section{João Perci Schiavon}

jpschiavon@hotmail.com 